\title{
Preferences and Acceptance of Colorectal Cancer Screening in Thailand
}

\author{
Udomsak Saengow $^{1 *}$, Virasakdi Chongsuwiwatvong ${ }^{1}$, Alan Geater ${ }^{1}$, Stephen \\ Birch $^{2}$
}

\begin{abstract}
Colorectal cancer (CRC) is now common in Thailand with an increase in incidence over time. Health authorities are planning to implement a nationwide CRC screening program using fecal immunochemical test (FIT) as a primary screening tool. This study aimed to estimate preferences and acceptance of FIT and colonoscopy, explore factors influencing the acceptance, and investigate reasons behind choosing and rejecting to screen before the program was implemented. Patients aged 50-69, visiting the primary care unit during the study period, were invited to join this study. Patients with a history of cancer or past CRC screening were excluded. Face-to-face interviews were conducted. Subjects were informed about CRC and the screening tests: FIT and colonoscopy. Then, they were asked for their opinions regarding the screening. The total number of subjects was $437(86.7 \%$ response rate). Fifty-eight percent were females. The median age was 58 years. FIT was accepted by $74.1 \%$ of subjects compared to $\mathbf{5 5 . 6 \%}$ for colonoscopy. The acceptance of colonoscopy was associated with perceived susceptibility to CRC and family history of cancer. No symptoms, unwilling to screen, healthy, too busy and anxious about diagnosis were reasons for refusing to screen. FIT was preferred for its simplicity and non-invasiveness compared with colonoscopy. Those rejecting FIT expressed a strong preference for colonoscopy. Subjects chose colonoscopy because of its accuracy; it was refused for the process and complications. If the screening program is implemented for the entire target population in Thailand, we estimate that 106,546 will have a positive FIT, between 8,618 and 12,749 identified with advanced adenoma and between 2,645 and 3,912 identified with CRC in the first round of the program.
\end{abstract}

Keywords: Colorectal cancer - screening - preference - acceptance - Thailand

Asian Pac J Cancer Prev, 16 (6), 2269-2276

\section{Introduction}

In Thailand, colorectal cancer (CRC) is the third and fifth most common cancer in men and women respectively. From 1990 to 2005, age-standardized incidence rates (per 100000 persons per year) increased 54\% in men (from 8.4 to 12.9 ) and $61 \%$ in women (from 5.7 to 9.2) (National Cancer Institute, 2012). Many Asian countries reported similar trends (Center et al., 2009). Population aging, adopting a western diet and increasing sedentary behavior contribute to these increasing trends (Popkin, 1994; Zhang et al., 2012). GLOBOCAN 2012 projected that the number of annual new cases in Thailand will double during 2012-2035 (Ferlay et al., 2014).

The WHO suggests countries set up organized screening programs to tackle the problem (Miller, 2007). The screening aims to detect advanced adenoma (precancerous stage) and early cancer of which treatments could reduce the cancer incidence and mortality respectively (U. S. Preventive Services Task Force, 2008). Incidence rates of CRC have decreased in US and reached a plateau in Canada and New Zealand as a result of the screening (Jemal et al., 2010). The United States Preventive Services Task Force (USPSTF) recommends these screening modalities: stool test, sigmoidoscopy and colonoscopy. The target population for screening includes those aged 50-75 years without other risk factors (the 'average risk' population).

The Thai health authorities - including the Ministry of Public Health, the National Health Security Office (NHSO) and the National Cancer Institute - are planning to introduce a nationwide CRC screening program as a part of the National Cancer Control Program (2013-2017) (Hfocus, 2013; National Cancer Institute, 2013). The program will offer the fecal immunochemical test (FIT) to individuals aged 50 and above (the upper age limit and screening interval are still being considered) (International Health Policy Program, 2012; National Cancer Institute, 2013). The health care system in Thailand provides universal health care coverage through public health insurance schemes including the Civil Servant Medical Benefit Scheme (CSMBS) for government employees and 


\section{Udomsak Saengow et al}

their dependants, the Social Security Scheme (SSS) for private employees in the formal sector and the Universal Coverage Scheme (UCS) for the rest of the population (Bureau of Policy and Strategy, 2009; Hanvoravongchai, 2013). UCS is the first scheme to adopt the screening (National Cancer Institute, 2013).

FIT works by detecting occult blood in the stool, a proxy for presence of adenoma and cancer. Nevertheless, a number of conditions can cause a positive result. Therefore, individuals with a positive result require colonoscopy for their definitive diagnosis. FIT is a novel stool test; it requires neither diet restriction nor bowel preparation. No direct complication from FIT has been reported. Stool tests are typically done on an annual basis (U. S. Preventive Services Task Force, 2008; Shim et al., 2010; International Cancer Screening Network, 2014). Colonoscopy involves inserting an endoscope into the colon via the rectum. It requires one to three days of bowel preparation with complications varying from mild discomfort to bowel perforation (which can be fatal). Colonoscopy is performed once in 10 years (U. S. Preventive Services Task Force, 2008). Besides its diagnostic capability for cases with a positive stool test, colonoscopy can be employed as a first-line screening test. The sensitivity of FIT is $20.0-59.0 \%$ for advanced adenoma and 65.8-94.1\% for cancer. This compares with sensitivity of colonoscopy between $88.2-100.0 \%$ for both advanced adenoma and cancer. The specificity of FIT for CRC is between 87.5-94.6\% compared to $100.0 \%$ for colonoscopy (Rex et al., 1997; Nakama et al., 2001; Pickhardt et al., 2003; Bressler et al., 2007; Levi et al., 2007). Both FIT and colonoscopy are regarded as costeffective screening tests (U.S. Preventive Services Task Force, 2008; Barouni et al., 2012).

Whereas sensitivity and specificity indicate effectiveness of each screening test, an uptake rate dictates effectiveness of the overall screening program. National screening programs in Canada, US, UK, Italy, Korea and Singapore experienced challenges of low uptake despite differences in program administration, screening tests offered and health care financing (Choi et al., 2010; Lisi et al., 2010; Nnoaham et al., 2010; Centers for Disease Control and Prevention, 2011; Major et al., 2013; Suh et al., 2013; Wong et al., 2013). For example, in Singapore a co-payment program using stool and endoscopic tests, the uptake was $26.7 \%$ (Wong et al., 2013). In the UK a NHS program, using fecal occult blood test had $57.3 \%$ uptake (Nnoaham et al., 2010). The publicly-funded programs in Canada using stool tests, uptake was $16.1 \%$ (Major et al., 2013). One study in Malaysia reported extremely low screening rate $(0.7 \%)$ within past five years (Yusoff et al., 2012). We might therefore expect the introduction of similar screening programs in Thailand to face the same problem of low uptake.

Since individuals with a positive FIT are referred for colonoscopy, adherence to follow-up colonoscopy is as important as the initial uptake. Relative to the initial uptake, adherence rates to follow-up colonoscopy are relatively high - varying from $38.6 \%$ in Korea to $93.0 \%$ in Italy (Choi et al., 2012; Parente et al., 2013). Given its key role in the screening pathway, adherence to follow- up colonoscopy should be considered in addition to an initial uptake rate.

We conducted this study to determine preferences and acceptances of FIT and colonoscopy. This knowledge provides clues to an uptake rate of the screening program. Factors influencing acceptance of each test were identified along with reasons for accepting and rejecting it. Finally, the number of patients with advanced adenoma and CRC diagnosed during the first round of screening were estimated, shedding light on future incidence and mortality reduction and burden of screening to the health care system. Our results can facilitate health care planners to maximize performance of the screening program.

\section{Materials and Methods}

This study was conducted at Songklanagarind Hospital, a medical-school hospital operated by Prince of Songkla University, Songkhla Province. The Ethics Committee of the institute reviewed and approved the study protocol. The eligible subjects were patients aged 50-69 years, visiting the primary care clinic during JuneAugust 2013. We excluded patients with a history of any cancer or past CRC screening. All patients visited the clinic during the study period were approached and assessed for their eligibility. If they satisfied our eligibility criteria, the interviewer explained the study rationale and objectives and requested their written consent.

Uptake rates varied widely between countries and previous literature on uptake of CRC screening in Thailand was not available (at the time this study was conducted). Therefore, the sample size was calculated to estimate an uptake rate of 50\%; at this level of uptake, the sample size was largest given other parameters fixed. This mitigated the concern over insufficient sample size. The margin of error was set at $5 \%$. The significance level was 0.05 . After offsetting $10 \%$ of possibly incomplete data, the required sample size was 428 .

A face-to-face interview followed a structured questionnaire that collected data on demographic characteristics, socio-economic status, health insurance coverage, current health status, medical history, family history, perceived risk of developing CRC, and risk attitudes toward health gains and losses (Breyer and Fuchs, 1982). Then, interviewers informed subjects about incidence rates, risk of CRC in Thai population, its treatments and survival rates of CRC patients.

Afterwards, interviewers provided information about CRC and screening tests to subjects by reading out the information sheets verbatim. The contents included general knowledge about CRC, risk of developing CRC in Thai population and information regarding both screening tests - FIT and colonoscopy. Information about screening tests consisted of process, complications, sensitivity, false positive rate and potential reduction in incidence and mortality rates. The pictures of instruments used in each test were presented to subjects along with related information. The screening frequencies were once a year for FIT and once in 10 years for colonoscopy. After all information was read out to subjects, the key messages summarized in a single poster were presented to subjects. 
Preferences and Acceptance of Colorectal Cancer Screening in Thailand

This enabled subjects to review all relevant information before answering subsequent questions.

Each subject was asked if they would be willing to participate in the CRC screening program without user fees. If they answered "no", the interviewer would ask reasons behind their unwillingness. If they answered "yes", the interviewer would ask them to choose their preferred screening test and explore reasons for their preference. Finally, the interviewer asked whether the subject was willing to screen with the other test if the test they had chosen was unavailable. If they rejected the alternative, their reasons would be explored.

All data analyses were performed using "epicalc" package on $\mathrm{R}$ version 3.0.2 (Chongsuvivatwong, 2012; $\mathrm{R}$ Core Team, 2013). Acceptance rates of screening, acceptance rates by selected factors and screening preferences were reported. Chi-squared and Fisher's exact test were used to test for statistical significance in the

Table 1. Characteristics of Study Subjects and Acceptance Rates of FIT and Colonoscopy Stratified by Each Characteristic

\begin{tabular}{|c|c|c|c|c|c|}
\hline \multirow[b]{2}{*}{ Characteristic } & \multirow{2}{*}{$\begin{array}{c}\text { Frequency } \\
(\%)\end{array}$} & \multicolumn{2}{|l|}{ FIT } & \multicolumn{2}{|c|}{ Colonoscopy } \\
\hline & & Acceptance rate $(\%)$ & P-value $\left(\chi^{2}\right)$ & Acceptance rate (\%) & P-value $\left(\chi^{2}\right)$ \\
\hline Overall & $437(100.0)$ & 74.1 & - & 55.6 & - \\
\hline Gender & & & 0.86 & & 0.09 \\
\hline Male & $183(41.9)$ & 74.9 & & 60.7 & \\
\hline Female & $254(58.1)$ & 73.6 & & 52 & \\
\hline Age (years) & & & 0.23 & & 0.22 \\
\hline $50-54$ & $119(27.2)$ & 70.6 & & 55.5 & \\
\hline $55-59$ & $138(31.6)$ & 79.7 & & 62.3 & \\
\hline $60-64$ & $111(25.4)$ & 74.8 & & 50.5 & \\
\hline $65-69$ & $69(15.8)$ & 68.1 & & 50.7 & \\
\hline Health insurance scheme & & & $0.19^{\mathrm{F}}$ & & $0.38^{\mathrm{F}}$ \\
\hline UCS & $100(22.9)$ & 76 & & 57 & \\
\hline SSS & $35(8.0)$ & 85.7 & & 65.7 & \\
\hline CSMBS & $297(68.0)$ & 71.7 & & 53.9 & \\
\hline Education level & & & 0.38 & & 0.54 \\
\hline Grade 6 or below & $116(26.5)$ & 75.9 & & 50 & \\
\hline Grade 7 - Grade 12 & $120(27.5)$ & 78.3 & & 56.7 & \\
\hline Bachelor's degree & $143(32.7)$ & 72 & & 58.7 & \\
\hline > Bachelor's degree & $58(13.3)$ & 67.2 & & 56.9 & \\
\hline Marital status & & & $0.75^{\mathrm{F}}$ & & $0.30^{\mathrm{F}}$ \\
\hline Married & $363(83.1)$ & 74.9 & & 57.3 & \\
\hline Single & $19(4.3)$ & 68.4 & & 36.8 & \\
\hline Separated & $15(3.4)$ & 66.7 & & 53.3 & \\
\hline Widowed & $40(9.2)$ & 72.5 & & 50 & \\
\hline Employment status & & & 0.38 & & 0.71 \\
\hline Employee & $151(34.6)$ & 72.2 & & 56.3 & \\
\hline Business owner & $120(27.5)$ & 80 & & 59.2 & \\
\hline Retired & $106(14.3)$ & 70.8 & & 51.9 & \\
\hline Home-maker & $60(13.7)$ & 73.3 & & 53.3 & \\
\hline Household income per mo & & & 0.61 & & 0.09 \\
\hline $0-30000$ & $167(38.2)$ & 74.3 & & 52.7 & \\
\hline $30001-60000$ & $125(28.6)$ & 78.4 & & 53.6 & \\
\hline$>60000$ & $127(29.1)$ & 73.2 & & 64.6 & \\
\hline Perceived susceptibility to & & & $0.27^{\mathrm{F}}$ & & 0.05 \\
\hline Low & $289(76.9)$ & 71.6 & & 51.9 & \\
\hline Average & $67(17.8)$ & 79.1 & & 65.7 & \\
\hline High & $20(5.3)$ & 85 & & 70 & \\
\hline Knowing someone with $\mathrm{C}$ & & & $0.03 *$ & & 0.43 \\
\hline No & $338(77.3)$ & 71.6 & & 54.4 & \\
\hline Yes & $99(22.7)$ & 82.8 & & 59.6 & \\
\hline Family history of cancer ( & & & 0.42 & & 0.14 \\
\hline No & 314 (71.9) & 77.2 & & 58 & \\
\hline Yes & $123(28.1)$ & 72.9 & & 49.6 & \\
\hline Company present during $\mathrm{h}$ & sits & & 0.12 & & 0.25 \\
\hline No & $249(57)$ & 71.1 & & 53 & \\
\hline Yes & $188(43)$ & 78.2 & & 59 & \\
\hline Purchasing private health & & & 0.19 & & $0.02 *$ \\
\hline No & $334(76.4)$ & 72.5 & & 52.4 & \\
\hline Yes & $103(23.6)$ & 79.6 & & 66 & \\
\hline
\end{tabular}

FIT=fecal immunochemical test; UCS=Universal Coverage Scheme; CSMBS=Civil Servant Medical Benefit Scheme; SSS=Social Security Scheme; $\mathrm{THB}=$ Thai baht; $\mathrm{CRC}=$ colorectal cancer; ${ }^{\mathrm{F}}$ Fisher's exact $\mathrm{p}$-value; $* \mathrm{p}<0.05$ 
Udomsak Saengow et al

bivariate analysis. Factors influencing acceptance were identified using logistic regression. The final model was selected according to its Akaike Information Criterion value.

As mentioned earlier about the proposed CRC screening program in Thailand, we finally estimated the potential number of individuals with positive FIT, advanced adenoma and CRC identified in the first round of screening. We anticipated that the target group for screening is Thai citizens aged 50-69. By assuming that subjects who accepted the test will utilize it when the screening program is carried out, age-and genderadjusted acceptance rates for FIT and colonoscopy were employed as uptake rates of the program. To complete the calculation, we obtained population data from the NHSO database (National Health Security Office, 2014) and screening performances from the pilot screening conducted in North Thailand (Khuhaprema et al., 2014).

\section{Results}

A total 504 eligible individuals were approached by interviewers; 437 provided their written consents (response rate $86.7 \%$ ). Figure 1 demonstrates overall acceptance of the screening program and screening method preference. Four-fifths of subjects showed their interest in the CRC screening program. They preferred FIT over colonoscopy as a screening test. Small portion of subjects expressed indifferent preferences for both tests. FIT was also widely accepted among subjects who preferred colonoscopy. In contrast, less than half of those who preferred FIT accepted colonoscopy.

In total, the acceptance rate was $74.1 \%$ for FIT and $55.6 \%$ for colonoscopy . Table 1 shows characteristics of study subjects and acceptance rates of each test stratified by each characteristic. Nearly $60 \%$ of subjects were female. The median age was 58 years. As indicated by chi-squared test, subjects who know someone with CRC had higher chance to accept FIT. Those purchased private health insurance were more likely to accept colonoscopy.

The results of logistic regression models were shown in Table 2. Subjects from the highest education group were less likely to accept FIT; although, overall effects of education was insignificant. Perceived susceptibility

Table 2. Factors Influencing Acceptance of FIT and Colonoscopy

\begin{tabular}{|c|c|c|c|c|c|c|c|c|}
\hline \multirow{3}{*}{ Variable } & \multicolumn{4}{|c|}{ FIT } & \multicolumn{4}{|c|}{ Colonoscopy } \\
\hline & \multirow[t]{2}{*}{ OR } & \multirow[t]{2}{*}{$95 \% \mathrm{CI}$} & \multicolumn{2}{|c|}{ P-value } & \multirow[t]{2}{*}{ OR } & \multirow[t]{2}{*}{$95 \% \mathrm{CI}$} & \multicolumn{2}{|c|}{ P-value } \\
\hline & & & Wald & LR & & & Wald & LR \\
\hline Gender & & & & 4.39 & & & & 0.21 \\
\hline Male & reference & & & & reference & & & \\
\hline Female & 0.81 & $0.48-1.38$ & 0.44 & & 0.74 & $0.46-1.18$ & 0.21 & \\
\hline Age group (years) & & & & 0.31 & & & & 0.31 \\
\hline $50-54$ & reference & & & & reference & & & \\
\hline $55-59$ & 1.87 & $0.96-3.66$ & 0.07 & & 1.76 & $0.98-3.16$ & 0.06 & \\
\hline $60-64$ & 1.39 & $0.71-2.73$ & 0.34 & & 1.33 & $0.72-2.48$ & 0.36 & \\
\hline $65-69$ & 1.2 & $0.55-2.64$ & 0.65 & & 1.29 & $0.62-2.66$ & 0.49 & \\
\hline Household income per month (THB) & & & & 0.42 & & & & 0.62 \\
\hline $0-30000$ & reference & & & & reference & & & \\
\hline $30001-60000$ & 1.54 & $0.77-3.08$ & 0.22 & & 0.94 & $0.52-1.73$ & 0.85 & \\
\hline$>60000$ & 1.13 & $0.53-2.42$ & 0.74 & & 1.27 & $0.64-2.51$ & 0.5 & \\
\hline Education level & & & & 0.25 & & & & 0.57 \\
\hline Grade 6 or below & reference & & & & reference & & & \\
\hline Grade 7 - Grade 12 & 0.64 & $0.30-1.39$ & 0.26 & & 0.88 & $0.45-1.71$ & & \\
\hline Bachelor's degree & 0.53 & $0.23-1.24$ & 0.15 & & 1.33 & $0.64-2.76$ & & \\
\hline$>$ Bachelor's degree & 0.36 & $0.13-0.97$ & $0.04 *$ & & 0.95 & $0.39-2.34$ & & \\
\hline Health insurance scheme & & & & 0.32 & & & & 0.08 \\
\hline UCS & reference & & & & reference & & & \\
\hline SSS & 1.81 & $0.50-6.57$ & 0.37 & & 1.24 & $0.45-3.44$ & 0.68 & \\
\hline CSMBS & 0.8 & $0.38-1.68$ & 0.55 & & 0.56 & $0.29-1.08$ & 0.09 & \\
\hline Perceived susceptibility to CRC & & & & 0.34 & & & & $0.04 *$ \\
\hline Low & reference & & & & reference & & & \\
\hline Average & 1.25 & $0.64-2.45$ & 0.51 & & 1.72 & $0.95-3.09$ & 0.07 & \\
\hline High & 2.41 & $0.63-9.19$ & 0.2 & & 2.69 & $0.95-7.65$ & 0.06 & \\
\hline Purchasing private health insurance & & & & 0.06 & & & & 0.08 \\
\hline No & reference & & & & reference & & & \\
\hline Yes & 1.84 & $0.97-3.51$ & 0.06 & & 1.63 & $0.95-2.80$ & 0.08 & \\
\hline Knowing someone with CRC & & & & 0.07 & & & & \\
\hline No & reference & & & & NS & & & \\
\hline Yes & 1.76 & $0.94-3.27$ & 0.08 & & NS & & & \\
\hline Family history of cancer (any types) & & & & & & & & $0.01 *$ \\
\hline No & NS & & & & reference & & & \\
\hline Yes & NS & & & & 0.53 & $0.32-0.87$ & $0.01 *$ & \\
\hline
\end{tabular}

FIT=fecal immunochemical test; $\mathrm{OR}=$ odds ratio; $95 \% \mathrm{CI}=95 \%$ confidence interval; Wald=Wald test; $\mathrm{LR}=$ likelihood ratio test; THB=Thai baht; UCS=Universal Coverage Scheme; SSS=Social Security Scheme; CSMBS=Civil Servant Medical Benefit Scheme; CRC = colorectal cancer; $\mathrm{NS}=$ not statistically significant; $* \mathrm{p}<0.05$ 
Table 3. Reasons for Choosing and Rejecting FIT and Colonoscopy

\begin{tabular}{lccr}
\hline Reason for choosing & Frequency $(\%)$ & Reason for rejecting & Frequency $(\%)$ \\
\hline FIT $^{\mathrm{a}}$ & \multicolumn{3}{c}{ FIT $^{\mathrm{b}}$} \\
$\quad$ Anxious about colonoscopy process & $43(23.2)$ & Only want to screen with colonoscopy & $15(62.5)$ \\
FIT is convenient & $42(22.7)$ & FIT is inconvenient & $2(8.2)$ \\
$\quad$ No pain & $34(18.4)$ & Too frequent screening & $2(8.2)$ \\
Colonoscopy & & Colonoscopy & \\
$\quad$ Colonoscopy is accurate & $91(59.9)$ & Anxious about colonoscopy process & $44(41.9)$ \\
Less frequent screening & $33(21.7)$ & Initial screening should be FIT & $10(9.5)$ \\
Providing quicker definitive diagnosis & $22(14.5)$ & Too complicated process & $8(7.6)$ \\
\hline
\end{tabular}

FIT = fecal immunochemical test; ${ }^{\mathrm{a} O f} 185$ subjects who preferred FIT; ${ }^{\mathrm{b}} \mathrm{Of} 24$ subjects who were not willing to screen with FIT; ${ }^{\mathrm{c} O f} 152$ subjects who preferred colonoscopy; ${ }^{\mathrm{d}} \mathrm{Of} 105$ subjects who were not willing to screen with colonoscopy

Table 4. Estimated Number of Thais with a Positive FIT, Advanced Adenoma and CRC Identified in the First Round of the Screening Program

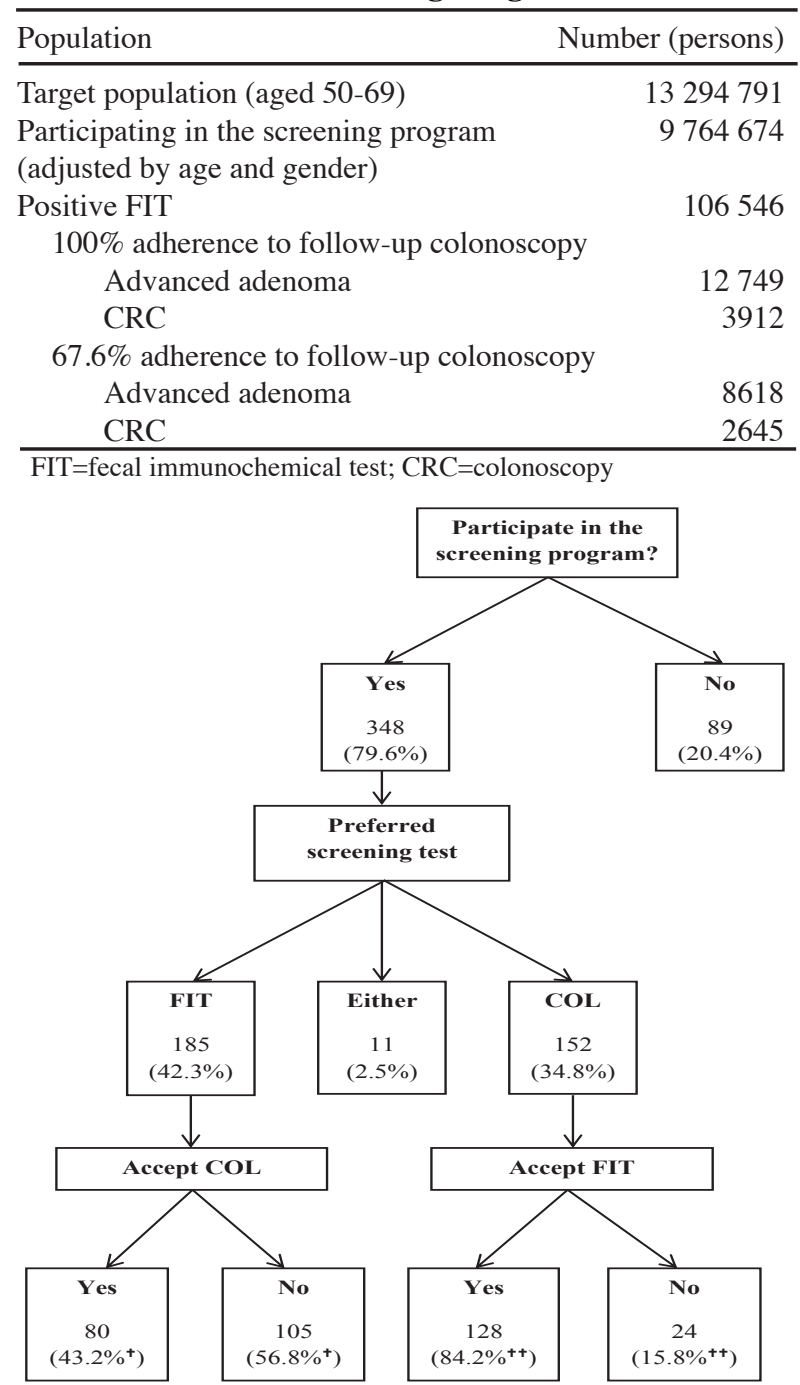

Figure 1. Screen Test Preference and Acceptance. $\mathrm{FIT}=$ fecal immunochemical test; $\mathrm{COL}=$ colonoscopy; Either=accepting both tests without preferring one over another. ${ }^{\dagger}$ denominator: 185 subjects who preferred FIT; ${ }^{+1}$ denominator: 152 subjects who preferred colonoscopy

to $\mathrm{CRC}$ was associated with acceptance of colonoscopy; those with higher perceived susceptibility tended to have greater acceptance. Acceptance of colonoscopy among subjects with family history of cancer was less than those without it.

Among 89 subjects who showed no interest in the screening, the leading reasons were no symptom (21.4\%), unwilling to screen $(12.4 \%)$, healthy $(11.2 \%)$ and too busy $(11.2 \%)$. The reasons - no symptoms and healthy-reflect misunderstandings of the purpose of cancer screening. The others indicate either lack of interest in screening or lack of awareness of the disease.

Table 3 summarizes top reasons for choosing and rejecting FIT and colonoscopy. Subjects who preferred FIT cited their concerns over colonoscopy as an explanation. In addition, the non-invasive nature of stool tests was among key reasons for choosing FIT. Those who rejected FIT stated their strong preference for colonoscopy. Accuracy and the related attributes were main reasons for preferring colonoscopy. Those who rejected colonoscopy referred to its process as a primary reason.

When the nationwide screening program is implemented in Thailand, we estimated that over 100 000 individuals with a positive FIT will be identified in the first round. The age- and gender-adjusted acceptance rates for FIT were used as an uptake rate of the program in this calculation. If adherence to colonoscopy among those with a positive FIT is $100 \%$, nearly 13000 cases of advanced adenoma and 3912 CRC patients will be diagnosed. However, the adherence rate of $100 \%$ might only happen in an ideal situation. Alternatively, we obtained the estimates based on the adherence rate of colonoscopy from our data. Since the Thailand proposed program merely offers screening with FIT, only those accepting FIT will utilize the screening. Therefore, we used the acceptance rate of colonoscopy among FIT - accepting subjects as the adherence rate for colonoscopy-that was $67.6 \%$. The estimates are concluded in Table 4.

\section{Discussion}

Among study subjects, FIT was preferred over colonoscopy. Perceived susceptibility to CRC and family history of cancer were associated with the acceptance of colonoscopy. Misunderstandings of the screening purposes led to lack of interest in screening. FIT was preferred for its simplicity and non-invasiveness compared with colonoscopy. However, those with strong preference for colonoscopy rejected screening with FIT. Colonoscopy was preferred for its accuracy and rejected for its process and complications. The first round of the screening program potentially identifies over 100000 positive FIT cases. Thousands of those would end up with advanced adenoma and CRC.

FIT outperformed colonoscopy regarding subjects' 
Udomsak Saengow et al

preferences. Other studies reported similar outcomes. Randomized controlled trials (RCTs) conducted in Spain and US reported higher uptake rates in the FIT arm compared with the colonoscopy arm (34\% versus $25 \%$ in a Spanish study, $41 \%$ versus $25 \%$ in a US study) (Quintero et al., 2012; Gupta et al., 2013). In a Hong Kong study, which allowed subjects to choose between FIT and colonoscopy, the majority (61\%) picked FIT after being informed about both tests (Wong et al., 2012). The high acceptance of FIT supports its use as the primary screening tool at the population level.

In this study, we implicitly treated the acceptance rates of screening tests as potential uptake and adherence of the proposed screening program. This should be carefully interpreted since our subjects did not represent general population. Rather, they were ones who had already accessed to care. Hence, the inference of the uptake rate from the acceptance rate is likely to provide an optimistic estimate. Previous studies supported this argument. They found the discrepancies between subjects' responses and their actual screening behaviors: the uptake rates estimated in the studies tended to be higher than the actual ones (Carson et al., 1996; Marshall et al., 2010). For the adherence to colonoscopy, our estimate was $67.6 \%$, whereas previous studies reported relatively high colonoscopy adherence among positive FIT cases: $87 \%$ in Spanish study, 92\% in Italian study, 96\% in Netherlands study and 79\% in UK study (Hol et al., 2010; Moss et al., 2012; Quintero et al., 2012; Parente et al., 2013).

The high acceptance of FIT provides the prospect for the proposed screening program in achieving the WHO recommended uptake of $70 \%$ (Miller, 2007). However, actual uptake rates of screening with FIT in many countries did not reach this goal: Spain $34.2 \%$, Italy $49.7 \%$, Netherlands $61.5 \%$, UK $61.8 \%$ and Australia $45.4 \%$ (Bowel Cancer Screening Pilot Monitoring and Evaluation Steering Committee, 2005; Hol et al., 2010; Moss et al., 2012; Quintero et al., 2012; Parente et al., 2013). Hence, we might regard the acceptance rate of FIT (74.1\%) as an upper bound of the actual uptake rate.

The acceptance of colonoscopy increased with perceived susceptibility. This association existed in other studies as well (Honda, 2004; Sun et al., 2004). As perceived susceptibility had no effects on FIT acceptance, FIT could attract wider range of population, regardless of their perceived susceptibility, at the initial screening step. This somewhat justifies the use of FIT as a primary screening tool. As effects of knowing someone with CRC was simultaneously adjusted for in the regression model, the variable - family history of cancer - indeed indicates subjects' familiarities with cancers other than CRC. Since effective screening is merely available for few types of cancer, familiarities with less preventable cancers might lead to lower likelihood of accepting colonoscopy.

Those unwilling to screen revealed their misunderstandings of the screening concepts. The similar misunderstandings were demonstrated in other studies (Hilmi et al., 2010; Suh et al., 2013). Hence, there is an opportunity to heighten acceptance of the screening program by correcting those misunderstandings. The recent study reported higher uptake rates in individuals who were informed about the screening (Hong and Kam, 2014). Those rejecting FIT revealed strong preference for colonoscopy. Health authorities might consider adding colonoscopy as an alternative primary screening tool. However, this complicates the screening logistics with small increase in overall acceptance of the program (5.5\%). Those rejecting colonoscopy cited its process and complications. The emphasis on very rare occurrence of severe complications (0.01-0.3\% for bowel perforation) (Waye et al., 1992; Misra et al., 2004; Quintero et al., 2012) may relieve their concerns. The other explanations for refusing to screen reported in present study were in common with previous studies (Yusoff et al., 2012; Tastan et al., 2013; Norwati et al., 2014).

From our crude estimation, the first round of screening potentially detects over 100000 cases with a positive FIT. Over 8000 to 13000 cases with advanced adenoma and between 2600 to 4000 cases with CRC will be diagnosed, whereas a number of new CRC cases in 2006 were 7000 (National Cancer Institute, 2012). As discussed earlier, uptake rates reported in this study might be overestimated; these potential numbers of positive FIT, adenoma and CRC cases should be interpreted as optimistic estimates or upper bounds of actual figures as well. The removal of advanced adenoma lowers the cancer incidence. The screening detects less advanced cancer (Cole et al., 2013), for which treatments can lower the mortality. However, the figures implied additional workloads to endoscopists, surgeons and others related health care workers as well as health care facilities. Health care planners should vigorously plan for health care system capacities to handle the burden of screening.

Our results support the use of FIT in the Thailand CRC screening program as it was widely accepted. In addition, FIT does not require specially-trained personnel and can be adopted at the sub-district health care centers as demonstrated in the pilot screening study (Khuhaprema et al., 2014). Informing public about the screening program will potentially raise its acceptance and uptake. Nevertheless, health care system should be prepared for increasing burden from the screening program. Further research should be conducted in different settings (e.g., provincial hospitals, community hospitals and health care centers) as well as in other regions of Thailand. Heath authorities can exploit this information and properly design the screening program.

\section{Acknowledgements}

The authors would like to acknowledge nurses and staff at the primary care clinic, Songklanagarind Hospital for their contribution to the data collecting. This study was supported by the Faculty of Medicine Graduate Study Grant [grant number 020 to U.S.], Faculty of Medicine, Prince of Songkla University.

\section{References}

Barouni M, Larizadeh MH, Sabermahani A, et al (2012). Markov's modeling for screening strategies for colorectal cancer. Asian Pac J Cancer Prev, 13, 5125-9. 
Bressler B, Paszat LF, Chen Z, et al (2007). Rates of new or missed colorectal cancers after colonoscopy and their risk factors: a population-based analysis. Gastroenterology, 132, 96-102.

Center MM, Jemal A, Ward E (2009). International trends in colorectal cancer incidence rates. Cancer Epidemiol Biomarkers Prev, 18, 1688-94.

Centers for Disease Control and Prevention (2011). Vital signs: Colorectal cancer screening, incidence, and mortality-United States, 2002-2010. MMWR Morb Mortal Wkly Rep, 60, 884-9.

Choi KS, Jun JK, Lee HY, et al (2010). Increasing uptake of colorectal cancer screening in Korea: a population-based study. BMC Public Health, 10, 265.

Choi KS, Lee HY, Jun JK, et al (2012). Adherence to followup after a positive fecal occult blood test in an organized colorectal cancer screening program in Korea, 2004-2008. J Gastroenterol Hepatol, 27, 1070-7.

Cole SR, Tucker GR, Osborne JM, et al (2013). Shift to earlier stage at diagnosis as a consequence of the National Bowel Cancer Screening Program. Med J Aust, 198, 327-30.

Gupta S, Halm EA, Rockey DC, et al (2013). Comparative effectiveness of fecal immunochemical test outreach, colonoscopy outreach, and usual care for boosting colorectal cancer screening among the underserved: a randomized clinical trial. JAMA Intern Med, 173, 1725-32.

Hanvoravongchai $\mathrm{P}$ (2013). Health financing reform in Thailand: toward universal coverage under fiscal constraints.

Hfocus (2013). Cabinet considering integration of 3 healthcare schemes for cancer treatments [Online]. Available: http:// www.hfocus.org/content/2013/12/5734.

Hilmi I, Hartono JL, Goh K (2010). Negative perception in those at highest risk--potential challenges in colorectal cancer screening in an urban Asian population. Asian Pac J Cancer Prev, 11, 815-22.

Hol L, van Leerdam ME, van Ballegooijen M, et al (2010). Screening for colorectal cancer: randomised trial comparing guaiac-based and immunochemical faecal occult blood testing and flexible sigmoidoscopy. Gut, 59, 62-8.

Honda K (2004). Factors associated with colorectal cancer screening among the US urban Japanese population. Am J Public Health, 94, 815-22.

Hong NS, Kam S (2014). Effectiveness of interventions to increase screening for gastric and colorectal cancer in Korea. Asian Pac J Cancer Prev, 15, 9147-51.

International Cancer Screening Network (2014). Inventory of colorectal cancer screening activities in ICSN countries, May 2008 [Online]. Available: http://appliedresearch.cancer.gov/ icsn/colorectal/screening.html [Accessed 9 January 2015].

Jemal A, Center MM, DeSantis C, et al (2010). Global patterns of cancer incidence and mortality rates and trends. Cancer Epidemiol Biomarkers Prev, 19, 1893-907.

Khuhaprema T, Sangrajrang S, Lalitwongsa S, et al (2014). Organised colorectal cancer screening in Lampang Province, Thailand: preliminary results from a pilot implementation programme. BMJ Open, 4, 003671.

Levi Z, Rozen P, Hazazi R, et al (2007). A quantitative immunochemical fecal occult blood test for colorectal neoplasia. Ann Intern Med, 146, 244-55.

Lisi D, Hassan C, Crespi M, et al (2010). Participation in colorectal cancer screening with FOBT and colonoscopy: an Italian, multicentre, randomized population study. Dig Liver Dis, 42, 371-6.

Major D, Bryant H, Delaney M, et al (2013). Colorectal cancer screening in Canada: results from the first round of screening for five provincial programs. Curr Oncol, 20, 252-7.

Miller A (2007). Cancer control: knowledge into action: WHO guide for effective programmes: Module 3 Geneva, World Health Organization.

Misra T, Lalor E, Fedorak RN (2004). Endoscopic perforation rates at a Canadian university teaching hospital. Can $J$ Gastroenterol, 18, 221-6.

Moss SM, Campbell C, Melia J, et al (2012). Performance measures in three rounds of the English bowel cancer screening pilot. Gut, 61, 101-7.

Nakama H, Zhang B, Zhang X (2001). Evaluation of the optimum cut-off point in immunochemical occult blood testing in screening for colorectal cancer. Eur J Cancer, 37, 398-401.

National Cancer Institute (2012). Cancer in Thailand: volume 6, 2004-2006, Bangkok.

National Cancer Institute (2013). National cancer control programmes (2013-2017), Bangkok, National Cancer Institute.

National Health Security Office (2014). Health insurance information service center [Online]. Available: http://eis. nhso.go.th/FrontEnd/Linkcontent.aspx ?menu=530000001 \&pid=540000025 [Accessed 30/05 2014].

Nnoaham KE, Frater A, Roderick P, et al (2010). Do geodemographic typologies explain variations in uptake in colorectal cancer screening? An assessment using routine screening data in the south of England. J Public Health (Oxf), 32, 572-81.

Norwati D, Harmy MY, Norhayati MN, et al (2014). Colorectal cancer screening practices of primary care providers: results of a national survey in Malaysia. Asian Pac J Cancer Prev, 15, 2901-4.

Parente F, Boemo C, Ardizzoia A, et al (2013). Outcomes and cost evaluation of the first two rounds of a colorectal cancer screening program based on immunochemical fecal occult blood test in northern Italy. Endoscopy, 45, 27-34.

Pickhardt PJ, Choi JR, Hwang I, et al (2003). Computed tomographic virtual colonoscopy to screen for colorectal neoplasia in asymptomatic adults. $N$ Engl $\mathrm{J} \mathrm{Med,} \mathrm{349,}$ 2191-200.

Popkin BM (1994). The nutrition transition in low-income countries: an emerging crisis. Nutr Rev, 52, 285-98.

Quintero E, Castells A, Bujanda L, et al (2012). Colonoscopy versus fecal immunochemical testing in colorectal-cancer screening. N Engl J Med, 366, 697-706.

Rex DK, Cutler CS, Lemmel GT, et al (1997). Colonoscopic miss rates of adenomas determined by back-to-back colonoscopies. Gastroenterology, 112, 24-8.

Shim JI, Kim Y, Han MA, et al (2010). Results of colorectal cancer screening of the national cancer screening program in Korea, 2008. Cancer Res Treat, 42, 191-8.

Suh M, Choi KS, Lee YY, et al (2013). Cancer screening in Korea, 2012: results from the Korean National Cancer Screening Survey. Asian Pac J Cancer Prev, 14, 6459-63.

Sun WY, Basch CE, Wolf RL, et al (2004). Factors associated with colorectal cancer screening among Chinese-Americans. Prev Med, 39, 323-9.

Tastan S, Andsoy, II, Iyigun E (2013). Evaluation of the knowledge, behavior and health beliefs of individuals over 50 regarding colorectal cancer screening. Asian Pac JCancer Prev, 14, 5157-63.

U. S. Preventive Services Task Force (2008). Screening for colorectal cancer: U.S. preventive services task force recommendation statement. Ann Intern Med, 149, 627-37.

Waye JD, Lewis BS, Yessayan S (1992). Colonoscopy: a prospective report of complications. J Clin Gastroenterol, 15, 347-51.

Wong MC, John GK, Hirai HW, et al (2012). Changes in the choice of colorectal cancer screening tests in primary care 
Udomsak Saengow et al

settings from 7,845 prospectively collected surveys. Cancer Causes Control, 23, 1541-8.

Wong RK, Wong ML, Chan YH, et al (2013). Gender differences in predictors of colorectal cancer screening uptake: a national cross sectional study based on the health belief model. BMC Public Health, 13, 677.

Yusoff HM, Daud N, Noor NM, et al (2012). Participation and barriers to colorectal cancer screening in Malaysia. Asian Pac J Cancer Prev, 13, 3983-7.

Zhang J, Dhakal IB, Zhao Z, et al (2012). Trends in mortality from cancers of the breast, colon, prostate, esophagus, and stomach in East Asia: role of nutrition transition. Eur $J$ Cancer Prev, 21, 480-9. 